\title{
Consorciação milho e feijão caupí para produção de espigas verdes e grãos verdes.
}

\author{
Paulo Sérgio L. Silva
}

ESAM - Departamento de Fitotecnia, C. Postal 137, 59.625-900 Mossoró-RN. E-mail: paulosergio@esam.br

\section{RESUMO}

O objetivo do presente trabalho foi avaliar o rendimento de espigas verdes de cultivares de milho (Centralmex, AG-401 e C-701) e o rendimento de feijão verde de cultivares de caupí (Pitiúba, Caicó e CNCx 658-15E) em monocultivos e em consorciação. O rendimento de espigas verdes (grãos com $70 \%$ a $80 \%$ de umidade) foi avaliado pelo peso de espigas comercializáveis, empalhadas (EE) ou despalhadas (ED). O rendimento de feijão (grãos com 60 a $80 \%$ de umidade) foi avaliado pelos rendimentos de vagens (RV) e de grãos verdes (RG). O estudo foi realizado em Mossoró (RN), entre abril e julho/1990. Três monocultivos de milho, três monocultivos de caupí e 3 × 3 consórcios foram avaliados no delineamento de blocos ao acaso com cinco repetições. As populações de plantas de milho e caupí, por hectare, foram 50.000 e 40.000 nos monocultivos, e 25.000 e 20.000 nos consórcios, respectivamente. Não existiu interação cultivares de milho x cultivares de caupí para as características avaliadas. A consorciação reduziu em 50\% EE e ED. A redução em RV e RG com a consorciação foi de 55\%. O índice Uso Eficiente da Terra (UET), calculado com EE e RV, foi maior com a cultivar Pitiúba do que com as outras cultivares de caupí. Não existiram diferenças entre cultivares de caupí quando UET foi calculado com ED e RG. Não existiram diferenças entre cultivares de milho quando o UET foi calculado com EE e RV ou ED e RG.

Palavras-chave: Zea mays L., Vigna unguiculata (L.) Walp., milho verde, feijão verde, uso eficiente da terra.

\begin{abstract}
Intercropping maize with cowpea for green ears and green grain production.

The objective was to evaluate the green ears yield of maize cultivars (Centralmex, AG-401 and C-701) and the green bean yield, of cowpea cultivars (Pitiúba, Caicó and CNCx 658-15E), using monocropping and intercropping systems. The green ears yield (grains with $70 \%-80 \%$ humidity) was evaluated by weight of marketable green ears, both with husk (EH) and without husk (EW). The green bean yield (grains with $60 \%$ - 80\% humidity) was evaluated by green pods yield (PY) and green grains yield (GY). The study was carried out at Mossoró, Brazil, between April and July, 1990. Three maize monocroppings, three cowpea monocroppings and $3 \times 3$ intercroppings were arranged in a randomized block design with five replications. The maize and cowpea plant populations, per hectare, were 50,000 and 40,000 with monocropping, and 25,000 and 20,000, with alternate-row intercropping, respectively. The maize cultivars $\mathrm{x}$ cowpea cultivars interaction was not significant for the traits evaluated. The intercropping systems reduced 50\% $\mathrm{EH}$ and $\mathrm{EW}$. The reduction of $\mathrm{PY}$ and GY by intercropping was 55\%. The Land Equivalent Ratio (LER) calculated from EH and PY was greater when intercropping was made with Pitiúba cultivar than with other cowpea cultivars. There were no differences among cowpea cultivars when LER was obtained from EW and GY. Maize cultivars did not differ as LER calculated from EH and PY or EW and GY.
\end{abstract}

Keywords: Zea mays L., Vigna unguiculata (L.) Walp., green corn, green bean, land equivalent ratio.

\section{(Aceito para publicação em 15 de janeiro de 2.001)}

$\mathrm{O}$ "milho verde", isto é, grãos de Zea mays L. com teor de umidade entre $70 \%$ e $80 \%$, e o feijão verde, ou seja, grãos de caupí (Vigna unguiculata (L.) Walp.) com teor de umidade entre $60 \%$ e $80 \%$, são produtos amplamente produzidos e consumidos no Rio Grande do Norte. Na realidade, os dois produtos possuem importância expressiva em todo o Nordeste brasileiro, sendo consumidos pelo nordestino sob várias formas, inclusive como ingredientes de pratos típicos da região.

Para produção dos dois produtos, milho e caupí são cultivados em monocultivo ou em variados tipos de consórcios, dentre os quais um dos mais comuns é aquele de fileiras alternadas das duas culturas. Aliás, grãos verdes e secos de milho e caupí são produzidos com as mesmas cultivares e práticas culturais. Não existem dados sobre os rendimentos médios de espigas verdes e de grãos verdes das duas culturas no Rio Grande do Norte. Para grãos secos, os rendimentos médios de milho e caupí no período 1993-95 foram de $464 \mathrm{~kg} \mathrm{ha}^{-1}$ e $327 \mathrm{~kg} \mathrm{ha}^{-1}$, respectivamente (Brasil, 1996). Vários problemas devem estar associados a estes baixos rendimentos. Um dos mais importantes é o plantio de cultivares tradicionais, com baixa capacidade produtiva. Em geral, o agricultor norte-riograndense semeia sua própria semente que, freqüentemente, é de uma mistura de cultivares. Está se tornando comum a semeadura de cultivares importadas de outras regiões do país e que sequer foram avaliadas sob as condições nordestinas. Portanto, a identificação de cultivares adequadas poderá contribuir para melhoria dos rendimentos de milho e caupí cultivados em monocultivo ou em consórcio.

Nos trabalhos mais recentes sobre a consorciação milho e caupí o interesse 
dos pesquisadores é o aumento da produção de forragem (Khandaker, 1994; Tripathy et al., 1997; Krishna et al., 1998), de grãos das duas culturas (Mohammad, 1993; Watiki et al., 1993; Myaka, 1995; Balyan, 1997; Khola et al., 1999;), ou o rendimento de uma terceira cultura plantada em sucessão ao consórcio (Balyan, 1997; Olasantan, 1998). Diferentes cultivares influenciam os rendimentos de forragem (Tripathy et al., 1997) e de grãos. No caso do caupí, a consorciação pode ou não reduzir o rendimento de grãos (Abdel-Gawad, 1993; Watiki et al., 1993). Por outro lado, para o milho, a consorciação com caupí propicia (Balyan, 1997; Skovgard \& Pats, 1997) ou não (Watiki et al., 1993) aumento no rendimento de grãos.

Apenas o trabalho de Silva \& Freitas (1996) foi encontrado na literatura consultada tratando da consorciação milhocaupí para produção de espigas verdes e de grãos verdes. Eles concluíram que o número e o peso de espigas verdes, por hectare, obtidos nos monocultivos foram superiores, em média, aos obtidos nos consórcios. Para o caupí, os monocultivos, em média, também foram superiores aos consórcios, mas a diferença entre monocultivo e a consorciação com uma das cultivares de milho (dentre as três estudadas) não foi significativa. Coelho \& Silva (1984) e Ramalho et al. (1985) estudaram o consórcio milho e feijão comum para a produção de espigas verdes e grãos maduros de feijão comum (Phaseolus vulgaris L.). Segundo Coelho \& Silva (1984), devido à redução de $15 \%$ na produção de espigas verdes comerciais de milho, no sistema consorciado, e considerando que o preço médio do feijão é cerca de quatro vezes o de espigas verdes de milho, a consorciação não se apresenta como alternativa vantajosa, no aproveitamento de várzeas na entressafra do arroz. Ramalho et al. (1985) também concluíram que, em diferentes épocas da entressafra, dificilmente o consórcio milho verde e feijão comum será vantajoso economicamente, pela redução da produção de espigas comerciais.

O presente trabalho teve como objetivo avaliar os rendimentos de espigas verdes de milho e de vagens e grãos verdes de caupí, em cultivos puros e consorciados.

\section{MATERIAL E MÉTODOS}

O experimento foi realizado na ESAM. Na tabela 1 são apresentados dados sobre alguns fatores climáticos medidos durante o período de realização do experimento.

O trabalho foi realizado sob condições de sequeiro, mas recebeu irrigação suplementar por aspersão. A lâmina líquida requerida para o milho $(5,6 \mathrm{~mm})$ foi calculada considerando-se ser de $0,40 \mathrm{~m}$ a profundidade efetiva do sistema radicular. $\mathrm{O}$ momento de irrigar teve por base a água retida no solo à tensão de 0,04 MPa. O turno de rega foi de um dia. As irrigações foram iniciadas quando as plantas tinham, aproximadamente 35 dias de idade e foram feitas até pouco antes das colheitas.

Três cultivares de milho (Centralmex, AG-401 e C-701) e três de caupí (Pitiúba, Caicó e CNCx 658$15 \mathrm{E})$ foram cultivadas em monocultivo e em consórcio, perfazendo um total de 15 tratamentos (três monocultivos de milho, três monocultivos de caupí e $3 \mathrm{x}$ 3 consórcios). Os consórcios resultaram da combinação, em esquema fatorial completo, das três cultivares de cada uma das culturas. Os tratamentos foram avaliados no delineamento experimental de blocos ao acaso com cinco repetições. A cultivar Centralmex é variedade de polinização livre, possui altura de planta em torno de $210 \mathrm{~cm}$ e foi utilizada como testemunha, dentre as cultivares de milho. As cultivares AG-401 e C-701 são híbridos duplos, com alturas de planta em torno de 170 e $150 \mathrm{~cm}$, respectivamente. As três cultivares de caupí são de crescimento indeterminado (tipo ramador). A cultivar Pitiúba foi utilizada como testemunha, na comparação das cultivares de caupí. As parcelas dos cultivos puros ficaram constituídas por três fileiras com $6 \mathrm{~m}$ de comprimento. Como área útil, considerouse a ocupada pela fileira central, eliminando-se uma cova em cada extremidade. Nos consórcios, as parcelas foram formadas por quatro fileiras com $6 \mathrm{~m}$ de comprimento. Como área útil, considerou-se a ocupada pelas duas fileiras centrais, eliminando-se uma cova em cada extremidade. Tanto nas culturas puras quanto nas consorciadas, a distância entre fileiras foi de $1,0 \mathrm{~m}$ e, entre covas de uma mesma fileira, o espaçamento foi de $0,4 \mathrm{~m}$ para o milho e de 0,5 m para o caupí. Nos consórcios, milho e caupí ocuparam fileiras alternadas.

O solo, um Argissolo Vermelho Amarelo (PVA), foi preparado com duas gradagens. A análise de uma amostra de solo, retirada de área vizinha à área experimental, indicou: $\mathrm{pH}=6,4 ; \mathrm{P}=18$ ppm; $\mathrm{K}^{+}=0,11 \mathrm{cmol}_{\mathrm{c}} \mathrm{dm}^{-3} ; \mathrm{Ca}^{2+}=1,6$ $\mathrm{cmol}_{\mathrm{c}} \mathrm{dm}^{-3} ; \mathrm{Mg}^{2+}=0,8 \mathrm{cmol}_{\mathrm{c}} \mathrm{dm}^{-3} ; \mathrm{Al}^{3+}$ $=0,0 \mathrm{cmol}_{\mathrm{c}} \mathrm{dm}^{-3} \mathrm{e} \mathrm{Na}^{+}=0,02 \mathrm{cmol}_{\mathrm{c}} \mathrm{dm}^{-3}$; O plantio foi feito em 22/4/1990, com cinco sementes por cova. Um desbaste foi efetuado aos 25 dias do plantio, deixando-se duas plantas por cova, para as duas culturas. O caupí recebeu, como adubação de plantio, $60 \mathrm{~kg}$ de $\mathrm{P}_{2} \mathrm{O}_{5}$ e 30

Tabela 1. Médias das temperaturas máximas e mínimas e da umidade relativa do ar e totais de insolação e precipitação mensais, durante o período de abril a julho de 1990. Mossoró, ESAM, 1990.

\begin{tabular}{lccccr}
\hline Meses de 1990 & $\begin{array}{c}\text { Temp. máx. } \\
\left({ }^{\circ} \mathbf{C}\right)\end{array}$ & $\begin{array}{c}\text { Temp. mín. } \\
\left({ }^{\circ} \mathbf{C}\right)\end{array}$ & $\begin{array}{c}\text { Umid. } \\
(\%)\end{array}$ & $\begin{array}{c}\text { Insol. } \\
(\mathbf{h})\end{array}$ & $\begin{array}{c}\text { Precip. } \\
(\mathbf{m m})\end{array}$ \\
\hline Abril & 33,4 & 24,0 & 72,0 & 229,6 & 82,9 \\
Maio & 34,2 & 23,0 & 71,9 & 244,5 & 124,0 \\
Junho & 34,0 & 22,3 & 64,3 & 229,5 & 10,9 \\
Julho & 34,4 & 22,6 & 64,1 & 251,4 & 5,3 \\
\hline
\end{tabular}


Tabela 2. Médias do rendimento de espigas verdes empalhadas comercializáveis de cultivares de milho em cultivos puros e em consórcio com cultivares de caupí. Mossoró, ESAM, 1990.

\begin{tabular}{|c|c|c|c|c|c|}
\hline \multirow{4}{*}{$\begin{array}{l}\text { Cultivares de } \\
\text { milho }\end{array}$} & \multirow{3}{*}{$\begin{array}{c}\text { Milho em } \\
\text { monocultivo }\end{array}$} & \multicolumn{3}{|c|}{ Milho consorciado } & \multirow{3}{*}{ Médias ${ }^{1}$} \\
\hline & & \multicolumn{3}{|c|}{ Cultivares de caupí } & \\
\hline & & Pitiúba & Caicó & CNCx 658-15E & \\
\hline & & & kg.ha-1 & & \\
\hline Centralmex & 11.728 & 5.625 & 5.397 & 6.075 & $7.206 \mathrm{~A}$ \\
\hline AG-401 & 9.986 & 5.947 & 5.333 & 5.399 & $6.666 \mathrm{~A}$ \\
\hline C-701 & 10.377 & 5.602 & 4.689 & 5.159 & $6.457 \mathrm{~A}$ \\
\hline Médias $^{1}$ & $10.697 \mathrm{a}$ & $5.725 b$ & $5.140 \mathrm{~b}$ & $5.544 \mathrm{~b}$ & - \\
\hline
\end{tabular}

${ }^{1}$ Médias seguidas pela mesma letra, na linha ou na coluna, não diferem entre si (Tukey, $5 \%$ ).

Tabela 3. Médias do rendimento de espigas verdes despalhadas comercializáveis de cultivares de milho em cultivos puros e consórcios com cultivares de caupí. Mossoró, ESAM, 1990.

\begin{tabular}{|c|c|c|c|c|c|}
\hline \multirow{3}{*}{$\begin{array}{l}\text { Cultivares de } \\
\text { milho }\end{array}$} & \multirow{3}{*}{$\begin{array}{c}\text { Milho em } \\
\text { monocultivo }\end{array}$} & \multicolumn{3}{|c|}{ Milho consorciado } & \multirow{3}{*}{ Médias } \\
\hline & & \multicolumn{3}{|c|}{ Cultivares de caupí } & \\
\hline & & Pitiúba & Caicó & CNCx 658-15E & \\
\hline & & & kg.ha-1 & & \\
\hline Centralmex & 5.920 & 2.765 & 2.782 & 3.170 & $3.659 \mathrm{~A}$ \\
\hline AG-401 & 5.245 & 3.003 & 2.616 & 2.879 & $3.436 \mathrm{~A}$ \\
\hline C-701 & 5.629 & 3.321 & 2.946 & 2.990 & $3.972 \mathrm{~A}$ \\
\hline Médias ${ }^{1}$ & $5.931 \mathrm{a}$ & $3.030 \mathrm{~b}$ & $2.781 \mathrm{~b}$ & $3.013 \mathrm{~b}$ & - \\
\hline
\end{tabular}

${ }^{1}$ Médias seguidas pela mesma letra, na linha ou na coluna, não diferem entre si (Tukey, $5 \%$ ).

$\mathrm{kg}$ de $\mathrm{K}_{2} \mathrm{O}$, por hectare. O milho, além destes adubos, recebeu também, no plantio, $35 \mathrm{~kg}$ de N/ha. Os adubos foram aplicados em sulcos, ao lado e abaixo dos sulcos de semeadura. Apenas o milho recebeu adubação em cobertura (65 kg de N/ha, aos 25 dias após o plantio). Como fontes de $\mathrm{N}, \mathrm{P}_{2} \mathrm{O}_{5}$ e $\mathrm{K}_{2} \mathrm{O}$ foram utilizados sulfato de amônio, superfosfato simples e cloreto de potássio, respectivamente. O controle de Spodoptera frugiperda Smith foi efetuado com pulverizações de deltamethrin (250 mL.ha), aos 7 e 15 dias após o plantio. As invasoras foram controladas por capinas realizadas aos 15 e 50 dias após o plantio.

Para o milho, foram avaliados os pesos de espigas empalhadas e despalhadas, comercializáveis. A colheita foi realizada em quatro etapas, de 75 a 85 dias após o plantio, à medida que os grãos atingiam o "ponto de milho verde". Como espigas empalhadas comercializáveis, foram consideradas as espigas com aparência adequada à comercialização e comprimento igual ou superior a $22 \mathrm{~cm}$. Como espigas despalhadas comercializáveis, foram consideradas as espigas com comprimento igual ou superior a $17 \mathrm{~cm}$ e com granação e sanidade satisfatórias. Para o caupí, foram avaliados os pesos de vagens e de grãos verdes $\left(\mathrm{kg} \cdot \mathrm{ha}^{-1}\right)$. A colheita foi realizada em nove etapas, de 45 a 75 dias após o plantio, à medida que os grãos atingiam o "ponto de feijão verde".

Os dados referentes às características avaliadas foram submetidos à análise de variância, seguindo-se as recomendações de Gomes (1982). Foram analisados também dados sobre o índice de Uso Eficiente da Terra (UET), tal como descrito por Mead \& Willey (1980). O UET indica a área de terra necessária com as culturas em monocultivo para proporcionar um rendimento equivalente ao obtido com as culturas associadas, considerando-se iguais áreas de terra cultivada (Mead \& Willey, 1980). Se AC, AS, BC e BS são os rendimentos das culturas A, consorciada e solteira, e B, consorciada e solteira, respectivamente, o UET é igual a $(\mathrm{AC} / \mathrm{AS})+(\mathrm{BC} / \mathrm{BS})$.

\section{RESULTADOS E DISCUSSÃO}

Para os rendimentos de espigas de milho verde comercializáveis, empalhadas ou despalhadas, houve efeito significativo de "milho (puros e consórcios)" (PC), mas não de "cultivares de milho" (M) ou da interação PC x M. $\mathrm{O}$ rendimento médio do milho nos monocultivos foi superior aos rendimentos médios nos sistemas consorciados, os quais não diferiram entre si, tanto para espigas empalhadas (Tabela 2) como para espigas despalhadas (Tabela 3). Para espigas empalhadas comercializáveis, o rendimento médio da gramínea nos consórcios foi de 5,5 t.ha ${ }^{-1}$. Este valor representa quase $51 \%$ do rendimento médio observado nas parcelas do milho solteiro. Para espigas despalhadas comercializáveis, o percentual correspondente $(50 \%)$ foi semelhante.

No que se refere aos rendimentos de vagens e grãos verdes de caupí, à semelhança do encontrado para o milho, houve efeito significativo de "caupí (puros 
Tabela 4. Médias do rendimento de vagens verdes de cultivares de caupí em cultivos puros e consórcios com cultivares de milho. Mossoró, ESAM, 1990.

\begin{tabular}{|c|c|c|c|c|c|}
\hline \multirow{4}{*}{$\begin{array}{l}\text { Cultivares de } \\
\text { caupí }\end{array}$} & \multirow{3}{*}{$\begin{array}{c}\text { Caupí em } \\
\text { monocultivo }\end{array}$} & \multicolumn{3}{|c|}{ Milho consorciado } & \multirow{3}{*}{ Médias ${ }^{1}$} \\
\hline & & \multicolumn{3}{|c|}{ Cultivares de milho } & \\
\hline & & Centralmex & AG-401 & C-701 & \\
\hline & & & kg.ha-1 & & \\
\hline Pitiúba & 3.876 & 2.427 & 2.107 & 2.737 & $2.787 \mathrm{~A}$ \\
\hline Caicó & 6.129 & 2.591 & 2.188 & 2.831 & $3.435 \mathrm{~A}$ \\
\hline CNCx 658-15E & 6.216 & 2.136 & 2.391 & 2.059 & $3.200 \mathrm{~A}$ \\
\hline Médias $^{1}$ & $5.407 \mathrm{a}$ & $2.385 \mathrm{~b}$ & $2.229 \mathrm{~b}$ & $2.542 \mathrm{~b}$ & - \\
\hline
\end{tabular}

${ }^{1}$ Médias seguidas pela mesma letra, na linha ou na coluna, não diferem entre si (Tukey, 5\%).

Tabela 5. Médias do rendimento de grãos verdes de cultivares de caupí em cultivos puros e consórcios com cultivares de milho. Mossoró, ESAM, 1990.

\begin{tabular}{|c|c|c|c|c|c|}
\hline \multirow{4}{*}{$\begin{array}{c}\text { Cultivares de } \\
\text { caupí }\end{array}$} & \multirow{3}{*}{$\begin{array}{c}\text { Caupí em } \\
\text { monocultivo }\end{array}$} & \multicolumn{3}{|c|}{ Milho consorciado } & \multirow{3}{*}{ Médias $^{1}$} \\
\hline & & \multicolumn{3}{|c|}{ Cultivares de milho } & \\
\hline & & Centralmex & AG-401 & C-701 & \\
\hline & & & kg.ha-1 & & \\
\hline Pitiúba & 2.106 & 1.336 & 1.150 & 1.409 & $1.500 \mathrm{~A}$ \\
\hline Caicó & 2.911 & 1.165 & 1.151 & 1.321 & $1.637 \mathrm{~A}$ \\
\hline CNCx 658-15E & 2.816 & 1.203 & 1.142 & 957 & $1.530 \mathrm{~A}$ \\
\hline Médias $^{1}$ & $2.611 \mathrm{a}$ & $1.235 \mathrm{~b}$ & $1.145 \mathrm{~b}$ & $1.229 \mathrm{~b}$ & - \\
\hline
\end{tabular}

${ }^{1}$ Médias seguidas pela mesma letra, na linha ou na coluna, não diferem entre si (Tukey, $5 \%$ ).

e consórcios)" (PC), mas não de "cultivares de caupí” (C) ou da interação PC x C. Os rendimentos médios de vagens (Tabela 4) e grãos (Tabela 5) verdes, obtidos nos consórcios, não diferiram entre si e foram inferiores aos respectivos rendimentos médios obtidos nos monocultivos. No caso do rendimento de vagens verdes, o rendimento médio dos consórcios $\left(2,4 \mathrm{t} \mathrm{ha}^{-1}\right)$ foi de apenas $44 \%$ do rendimento médio dos monocultivos $\left(5,4\right.$ t.ha $\left.{ }^{-1}\right)$. Para grãos verdes, o rendimento médio de 1,2 t.ha ${ }^{-1}$, obtido nos consórcios, foi de apenas $46 \%$ do rendimento médio dos monocultivos.

Os resultados obtidos no presente trabalho demonstram que a consorciação reduziu, significativamente, os rendimentos de espigas empalhadas e despalhadas, comercializáveis, em, aproximadamente, $50 \%$, em relação aos rendimentos dos monocultivos. Estas reduções devem ter sido devidas às menores populações do milho e à competição com o caupí, nos consórcios. Reduções no rendimento do milho, em conseqüência da consorciação têm sido observadas por outros autores. Silva \& Freitas (1996) constataram que os decréscimos médios para número e peso de espigas verdes, em decorrência da consorciação, foram de 49 e $45 \%$, respectivamente. Ramalho et al. (1985) verificaram reduções de $23 \%$ e $21 \%$ na produção de milho verde de duas cultivares consorciadas com feijão comum (Phaseolus vulgaris L.). Segundo eles, esta redução no rendimento de milho verde é de magnitude superior à normalmente relatada na literatura, envolvendo o consórcio milho e feijão comum, quando é avaliada a produção de grãos secos de milho. Para eles, a maior competição exercida pelo feijão, quando o milho se destina à produção de espigas verdes é, provavelmente, explicada pelo fato de, neste caso, ser menor a diferença no ciclo das culturas. Segundo Willey (1979), citado por Ramalho et al. (1985), quanto maior for a diferença no ciclo das culturas maior será a complementaridade temporal e menor a competição de uma espécie sobre a outra. Mas provavelmente outros fato- res devem estar envolvidos, dentre os quais a população de plantas e as cultivares de milho e feijão. Pereira Filho $e t$ al. (1991) verificaram variação de $+3 \%$ a $-34 \%$ no rendimento do milho consorciado em relação ao rendimento do milho solteiro, a depender da população de plantas (de 20 mil a 60 mil plantas/ha) e da cultivar de milho. Para uma população de 50 mil plantas/ha, Cruz et al. (1984) encontraram variação correspondente de $+14 \%$ a $-23 \%$, dependendo da cultivar. A variação observada por Carvalho (1990), foi de $-48 \%$ a $-57 \%$, também dependendo da cultivar, quando a população de milho foi de $20 \mathrm{mil}$ plantas/ha.

No caso do caupí, a redução dos rendimentos de vagens e de grãos verdes, em conseqüência da consorciação, ficou em torno de $55 \%$ e pode ser atribuída às menores populações de plantas do caupí nos consórcios, mas também à grande competição com o milho. Este efeito da população de plantas no consórcio milho e caupí para produção de grãos secos foi demonstrado por Rêgo Neto et al. (1982). Quando a população do caupí 
Tabela 6. Médias dos índices de uso eficiente da terra (UET) calculados com base no peso de espigas verdes empalhadas comercializáveis de cultivares de milho e peso de vagens verdes de cultivares de caupí. Mossoró, ESAM, 1990.

\begin{tabular}{lcclc}
\hline \multirow{2}{*}{ Cultivares de caupí } & \multicolumn{3}{c}{ Cultivares de milho } & \multirow{2}{*}{ Médias $^{1}$} \\
\cline { 2 - 4 } & Centralmex & AG-401 & C-701 & $1,23 \mathrm{~A}$ \\
\hline Pitiúba & 1,18 & 1,19 & 1,33 & $0,95 \mathrm{~B}$ \\
Caicó & 0,94 & 0,95 & 0,96 & $0,93 \mathrm{~B}$ \\
\hline CNCx 658-15E & 0,91 & 1,00 & 0,89 & - \\
\hline Médias $^{1}$ & $1,01 \mathrm{a}$ & $1,05 \mathrm{a}$ & $1,06 \mathrm{a}$ & - \\
\hline
\end{tabular}

${ }^{1}$ Médias seguidas pela mesma letra, na linha ou na coluna, não diferem entre si (Tukey, 5\%).

no consórcio correspondeu a $50 \%$ da população no monocultivo (caso do presente trabalho), a redução média no rendimento de três cultivares foi de 55\%. Quando a população do caupí no consórcio foi equivalente a $66 \%$ da população no monocultivo, a redução correspondente foi menor (38\%).

Silva \& Freitas (1996) verificaram que os rendimentos de vagens e grãos verdes de caupí nos consórcios milho verde e caupí verde nem sempre foram inferiores, significativamente, aos obtidos nos monocultivos. Assim, o rendimento médio de cultivares de caupí em consórcio com um híbrido duplo de milho de porte intermediário, apesar de ter sido $25 \%$ menor que o rendimento médio das cultivares de caupí em monocultivo, a diferença não foi significativa.

No presente estudo, para as duas culturas, não houve efeito significativo da interação entre cultivares de milho e de caupí, indicando que os rendimentos das cultivares de milho não dependeram das cultivares de caupí utilizadas nos consórcios e vice-versa. Silva \& Freitas (1996), também estudando a consorciação milho verde e caupí verde, concluíram não existir a interação cultivares de milho x cultivares de caupí, para os rendimentos de milho verde ou feijão verde. Ramalho et al. (1984) também não encontraram interação significativa entre as cultivares de feijão comum e as de milho, nem destas com os sistemas de consorciação, para produção de grãos secos. Contudo, Carvalho (1990) verificou que as cultivares de feijão comum interferiram diferentemente no rendimento das cultivares de milho, e estas mostraram, entre si, o mesmo comportamento em relação às cultivares de feijão.
A análise de variância dos índices de Uso Eficiente da Terra (UET) indicou efeito significativo apenas para cultivares de caupí. Isto ocorreu quando os índices foram calculados com base nos pesos de espigas empalhadas comercializáveis e de vagens verdes. $\mathrm{O}$ UET obtido com a consorciação das cultivares de milho com a cultivar de caupí Pitiúba foi, em média, superior aos UET's obtidos com as outras duas cultivares de caupí, os quais não diferiram entre si (Tabela 6). O valor de 1,23 para o UET obtido com a cultivar Pitiúba indica que, em média, os monocultivos exigiriam $23 \%$ mais de terra que os consórcios para que produzissem o mesmo que um hectare de consórcio. É possível que a superioridade média dos consórcios das cultivares de milho com a cultivar de caupí Pitiúba, em relação aos consórcios com as outras cultivares de caupí, esteja relacionada a uma melhor adaptação da cultivar Pitiúba aos consórcios, apesar da interação cultivares de milho $\mathrm{x}$ cultivares de caupí não ter sido significativa, como já foi visto. Em média, a diminuição do rendimento de vagens verdes da cultivar Pitiúba, nos consórcios, em relação ao rendimento no monocultivo, foi de $37 \%$ (Tabela 4). Por outro lado, para as cultivares Caicó e CNCx 658-15E, as diminuições correspondentes foram de $59 \%$ e $65 \%$, respectivamente (Tabela 4).

Quando os UET's foram calculados com base nos dados de peso de espigas despalhadas e peso de grãos, o valor correspondente à cultivar Pitiúba também foi superior aos correspondentes às outras duas cultivares de caupí, mas neste caso as diferenças não foram significativas . O valor médio do UET, neste caso, foi 1,03 .

$\mathrm{O}$ fato de terem sido encontradas diferenças significativas entre os UET's calculados com base no peso de espigas verdes empalhadas e peso de vagens verdes, mas não terem sido constatadas tais diferenças entre os UET's calculados com base no peso de espigas verdes despalhadas e peso de grãos verdes, está relacionado, obviamente, a diferenças nas relações peso de espigas despalhadas/peso de espigas empalhadas e peso de grãos verdes/peso de vagens verdes das cultivares avaliadas. Para as cultivares de milho Centralmex, AG-401 e C-701, a relação média rendimento de espigas despalhadas/rendimento de espigas empalhadas foi de 51, 52 e $62 \%$, respectivamente. Para as cultivares de caupí Pitiúba, Caicó e CNCx 658-15E, a relação média rendimento de grãos verdes/rendimento de vagens verdes foi de 54,48 e $48 \%$, respectivamente. No caso do milho, as diferenças nas relações podem estar associadas a uma maior ou menor proporção de palhas na espiga ou a um descarte maior ou menor de espigas empalhadas, quando da seleção das espigas despalhadas comercializáveis. Para o caupí, as diferenças nas relações devem estar relacionadas a diferenças na proporção de pericarpo nas vagens.

Não foram encontrados na literatura consultada, dados sobre o UET calculados rendimentos de espigas verdes empalhadas e vagens verdes ou com rendimentos de espigas verdes despalhadas e grãos verdes no consórcio milhocaupí. Para rendimentos de grãos secos das duas culturas, os valores do UET têm sido superiores ou inferiores a 1 a depender da densidade de plantio de milho (Watiki et al., 1993) e da estação de plantio (Shumba et al., 1990), dentre outros fatores. Nas maiores densidades de plantio, o UET ficou em torno de 1,1, 
enquanto nas menores densidades o valor deste índice foi inferior a 1,0 (Watiki et al., 1993). Em ano de pouca chuva, o UET não foi influenciado pela consorciação, mas quando a precipitação pluvial foi acima da média, a consorciação aumentou a produtividade da terra em 51\% (Shumba et al., 1990).

Deve ser ressaltado que a comparação dos valores de UET nos consórcios milho-caupí para produção de espigas verdes e vagens ou grãos verdes, com os valores de UET nos consórcios para produção de grãos secos das duas culturas, deve ser feita com cautela. No caso do milho, espigas verdes imprestáveis para a comercialização podem ser perfeitamente aproveitadas quando o interesse for por grãos secos.

\section{LITERATURA CITADA}

ABDEL-GAWAD, K.I. Evaluation of cowpea varieties for intercropping with sorghum and corn. Bulletin of Faculty of Agriculture, v. 44, n. 33, p. 571-585, 1993.

BALYAN, J.S. Performance of maize (Zea mays)based intercropping systems and their aftereffect on wheat (Triticum aestivum). Indian Journal of Agronomy, v. 42, n. 1, p. 26-28, 1997.

BRASIL. Instituto Brasileiro de Geografia e Estatística. Anuário estatístico do Brasil, Rio de Janeiro, v. 56, 1997.

CARVALHO, H.W.L. Cultivares de milho e de feijão em monocultivo e consorciado. I. Ensaio de rendimentos. Pesquisa Agropecuária Brasileira, Brasília, v. 25, n. 7, p. 1003-1010, 1990.
COELHO, A.M.; SILVA, B.G. Fontes de nitrogênio na consorciação milho verde e feijão cultivados em várzeas. In: CONGRESSO NACIONAL DE MILHO E SORGO, 15., 1984, Maceió, AL. Resumos dos trabalhos. Maceió: EPEAL, 1984. p. 77.

CRUZ, J.C.; CORRÊA, L.A.; RAMALHO, M.A.P.; SILVA, A.F.; OLIVEIRA, A.C. Avaliação de cultivares de milho associados com feijão. Pesquisa Agropecuária Brasileira, Brasília, v. 19, n. 2, p. 163-168, 1984.

GOMES, F.P. Curso de estatística experimental. 10. ed. Piracicaba: Nobel, 1982. 496 p.

KHANDAKER, Z.H. Effect of mixed cropping of maize (Zea mays) and cowpea (Vigna unguiculata) forage on fodder yield, chemical composition and its in vitro digestibility. Indian Journal of Animal Nutrition, v. 11, n. 1, p. 5557, 1997.

KHOLA, O.P.S.; DUBE, R.K.; SHARMA, N.K. Conservation and production ability of maize (Zea mays) legume intercropping systems under varying dates of sowing. Indian Journal of Agronomy, v. 44, n. 1, p. 40-46, 1999.

KRISHNA, A.; RAIKHELKAR, S.V.; REDDY, A.S. Effect of planting pattern and nitrogen on fodder maize (Zea mays) intercropped with cowpea (Vigna unguiculata). Indian Journal of Agronomy, v. 43, n. 2, p. 237-240, 1998.

MEAD, R.; WILLEY, R.W. The concept of a "Land Equivalent Ratio" and advantages in yields from intercropping. Experimental Agriculture, v. 16, p. 217-228, 1980.

MOHAMMAD, I.; TYAGY, R.C.; RAO, D.S.R.M. Studies of maize-legumes intercropping systems in relation to nitrogen levels. Farming Systems, v. 9, n. 1-2, p. 5658, 1993.

MYAKA, F.A. Effect of time of planting and planting pattern of different cowpea cultivars on yield of intercropped cowpea and maize in tropical sub-humid environment. Tropical Science, v. 35, n. 3, p. 274-279, 1995.
OLASANTAN, F.O. Effects of preceding maize (Zea mays) and cowpea (Vigna unguiculata) in sole cropping and intercropping on growth yield and nitrogen requiriment of okra (Abelmoschus esculentus). Journal of Agricultural Science, v. 131, n. 3, p. 293-298, 1998.

PEREIRA FILHO, I.A.; CRUZ, J.C.; RAMALHO, M.A.P. Produtividade e índice de espiga de três cultivares de milho em sistema de consórcio com o feijão comum. Pesquisa Agropecuária Brasileira, Brasília, v. 26, n. 5, p. 745-751, 1991.

RAMALHO, M.A.P.; COELHO, A.M.; TEIXEIRA, A.L.S. Consórcio de milho verde e feijão em diferentes épocas de plantio na entresafra. Pesquisa Agropecuária Brasileira, Brasília, v. 20, n. 7, p. 799-806, 1985.

RÊGO NETO, J.; PAIVA, J.B.; SANTOS, J.H.R.; ALVES, J.F. Efeitos do sistema de cultivo sobre a produção e seus componentes em feijãode-corda, Vigna sinensis (L.) Sarei. Ciência Agropecuária, v. 13, n. 1/2, p. 35-41, 1982.

SHUMBA, E.M.; DHLIWAYO, H.H.; MUKOKO, O.Z. The potential of maizecowpea intercropping in low raifall areas of Zimbabwe. Journal of Agricultural Research, v. 28, n. 1, p. 33-38, 1990.

SILVA, P.S.L.; FREITAS, C.J. Rendimentos de grãos verdes de milho e caupí em cultivos puros e consorciados. Revista Ceres, Viçosa, v. 43, n. 245, p. 28-38, 1996.

SKOVGARD, H.; PATS, P. Reduction of stemborer damage by intercropping maize with cowpea.Agriculture Ecosystems \& Environment, v. 62, n. 1, p. 13-19, 1997.

TRIPATHY, R.K.; PRADAN, L.; RATH, B.S. Performance of maize (Zea mays) and cowpea (Vigna unguiculata) forage intercropping system in summer. Indian Journal of Agronomy, v. 42, n. 1, p. 38-41, 1997.

WATIKI, J.M.; FUKAI, S.; BANDA, J.A.; KEATING, B.A. Radiation interception and growth of maize/cowpea intercrop as affected by maize plant density and cowpea cultivar. Field Crops Research, v. 35, n. 2, p. 123-133, 1993. 